\title{
Isolation of Polyoma Viruses Lacking Endonuclease HindllI Sites
}

\author{
D. M. ANDERSON, ${ }^{1}$ M. M. BENDIG, AND W. R. FOLK \\ Department of Biological Chemistry, The University of Michigan, Ann Arbor, Michigan 48109
}

Accepted May 30, 1978

\begin{abstract}
Spontaneous mutants of polyoma virus have been isolated which lack either one or both of the two endo HindIII cleavage sites present in polyoma DNA. Some of the mutants contain single base changes or small deletions at the HindIII site in the early region of the polyoma genome. Most of these mutants have a normal phenotype; however, one member of this group grows poorly in comparison with wild-type virus. Other mutants contain large deletions, have lost either of the HindIII sites, and appear to require complementation by helper viruses in order to complete their growth cycle.
\end{abstract}

Studies of mutationally altered polyoma and SV40 viruses have provided much of our current understanding of papovavirus biology. Many of these altered viruses were isolated after chemical mutagenesis using selections for conditional lethality (1). Because of the conditions used for mutagenesis, it is likely that many of these viruses are altered at more than one site. This has been confirmed for several early (SV40) and late (polyoma) gene mutants by recent studies $(2,3)$.

An alternate approach, that of isolating or constructing viruses with limited nucleotide alterations at specific sites, has been employed to great advantage in recent studies of SV40 gene expression (4-13). Our early attempts to isolate polyoma viruses with alterations at a single site, that cleaved by endo EcoRI, led to the detection of viral genomes with reassorted sequences in which the EcoRI site had been deleted (14, 15). In this report, we describe the isolation and partial characterization of viruses having alterations at either of the two endo HindIII sites in the polyoma genome. One site is in the early region of the viral genome and the other site is in the late region (Fig. 1).

Endo HindIII cleaves polyoma DNA at two sites (Fig. 1); linear molecules remaining after exhaustive digestion would, there-

\footnotetext{
'Present address: Roche Institute of Molecular Biology, Nutley, New Jersey 07110.
}

fore, be expected to have lost one of the sites. Such linear molecules can be recircularized in vitro or in vivo by virtue of the cohesive termini produced by endo HindIII (20).

Two separate preparations of purified Pasadena large plaque polyoma virus DNA $(2.6$ and $3.5 \mu \mathrm{g})$ from low multiplicity infections were exhaustively digested with endo HindIII (21) and were subjected to electrophoresis through $1 \%$ agarose gels. The arca of the gel where linear DNAs would be expected to migrate (no band of linear DNA was visible after staining with ethidium bromide (EtdBr)) was excised and the DNAs were recovered by hydroxylapatite chromatography of the solubilized gel (22). Subconfluent $3 \mathrm{~T} 6$ cells were infected at $32^{\circ}$ with the two samples of DNA, using DEAE-dextran $(23,24)$. After 10 days, the media and cells (which showed no CPE) were removed from these plates, frozen, and thawed. These preparations were replenished with vitamins, essential and nonessential amino acids (Gibco), glutamine (0.6 $\mathrm{mg} / \mathrm{ml})$, and calf serum $(5 \%, \mathrm{v} / \mathrm{v})$, and used to infect fresh subconfluent $3 \mathrm{~T} 6$ cells. Virus stocks were prepared when CPE became evident 5-10 days later. These virus stocks were used to infect whole mouse embryo (WME) cells at $32^{\circ}$, and form I viral DNAs were purified by $\mathrm{CsCl}-\mathrm{EtdBr}$ centrifugation of the Hirt supernatants. Upon digestion of these DNA preparations with endo HindIII and separation upon $1 \%$ agarose gels, it was 


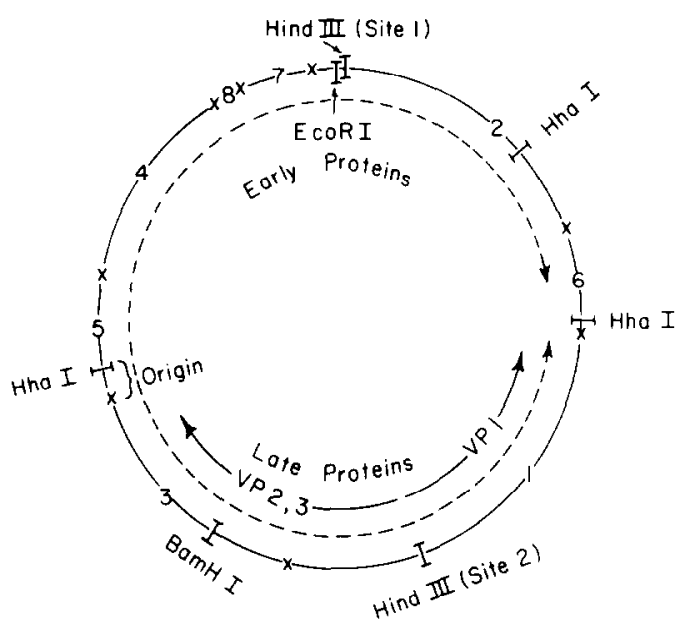

FIG. 1. Endonuclease sites in the polyoma genome. Sites cleaved by endonucleases EcoRI, HindIII, $H p a \mathrm{II}, \mathrm{BamHI}$, and $H h a \mathrm{I}(16,17)$ are indicated on the circular polyoma genome. HpaII fragments are numbered within the circle with cleavage sites given by $(x)$. Approximate division into early and late regions and location of structural proteins are taken from Refs. 18 and 19. Dashed line indicates polarities and approximate extents of early and late transcripts.

apparent that they contained significant numbers of DNA molecules which lacked one or both HindIII sites. Many of these DNAs were significantly smaller than wildtype polyoma DNA (Fig. 2a).

The endo HindIII-digested DNAs which migrated at the position of linear polyoma DNA were recovered from the gel and taken through another cycle of digestion, electrophoresis, and extraction from the gel. The linear DNAs were then used to infect WME cells in a plaque assay at $32^{\circ}$. Serial dilutions of the DNAs were used, and well isolated plaques were picked. Viruses from these plaques were absorbed to $3 \mathrm{~T} 6$ cells or WME cells at $32^{\circ}$, and $\left[{ }^{32} \mathrm{P}\right] \mathrm{DNAs}$ were prepared from the infected cells by Hirt extraction. Undigested and endo HindIII-digested DNA samples from each purified plaque were analyzed by electrophoresis through agarose gels.

Fifty-one plaques were picked, and all produced DNAs with altered endo HindIII digestion patterns. Some of the preparations contained viral DNA which appeared to be normal in size but which was cleaved only once by endo HindIII. Most of the preparations contained viral DNAs which were smaller than wild-type polyoma and which were cut only once or not at all by endo HindIII. Bccause many of the preparations contained two or more species of viral DNA, selected virus stocks were serially diluted and subjected to a second plaque purification at $32^{\circ}$. Stocks of virus were prepared with these twice-purified plaques and then were characterized.

The viruses were divided into two groups on the basis of their genome structure and requirement for complementing helpers (Table 1). Viruses placed in group I do not require complementing genomes in order to form plaques; whereas, viruses in group II appear to require complementation by other genomes in order to form plaques. Infection by viruses in the first group produced homogeneous populations of DNAs. Infection by viruses in the second group always produced two species of DNAs regardless of the number of attempts to plaque-purify them.

Digestion of DNAs from viruses in group I with endo HindIII produced linear DNAs. To identify which of the two HindIII sites is retained, each DNA preparation was digested with both endo EcoRI and endo HindIII (Fig. 2b). Every DNA produced two fragments approximately 55 and $45 \%$ the size of polyoma linears, indicating that all these mutants are altered at the HindIII site adjacent to EcoRI site (HindIII site 1, in the "early" region, Fig. 1). The sizes of the DNAs produced by viruses in group I, as measured by agarose gel electrophoresis, were not significantly different from that of wild-type polyoma DNA (Fig. 2b). Upon digestion of these DNAs with endo HaeIII, no significant alteration in electrophoretic mobility in $6 \%$ polyacrylamide gels of the 210 base pair HaeIII fragment containing the HindIII site 1 (fragment $\mathrm{H}$ (26); fragment $8(27)$ ) was observed. A deletion of 10 base pairs would have been detected.

Infection of mouse cells by viruses in group II generated viral DNAs which were smaller than polyoma DNA (between approximately 83 and $98 \%$ of wild-type size) and which were always mixtures of several species (Table 1). Even after several plaque purifications, mixtures of DNAs were produced, suggesting that the production of plaques by these viruses requires co-infection of cells by complementing genomes. 


$$
\overbrace{A B}^{W T} \overbrace{C D}^{1}{ }_{C T}^{2} \overbrace{F G}^{2}
$$

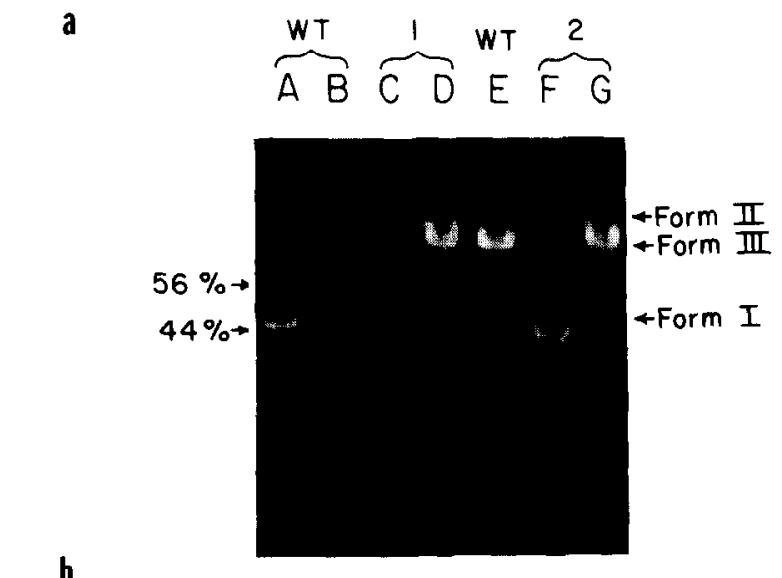

b

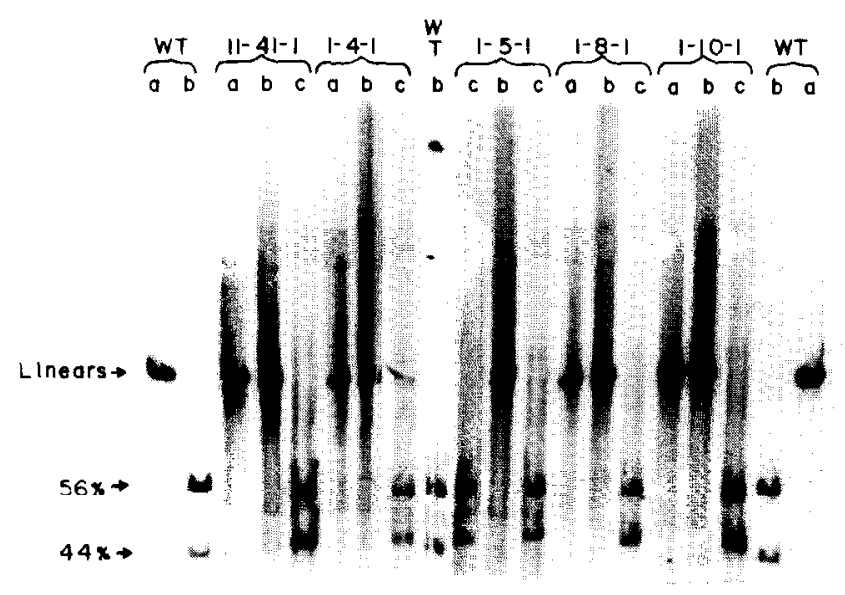

FIG. 2. (a) Electrophoresis of viral DNAs from HindIII-resistant enriched samples. Wild-type polyoma DNA or DNA samples enriched for HindIII-resistant molecules were subjected to electrophoresis through 1\% agarose gels (25) with (slots B, D, G) or without (slots A, C, F) digestion by endo HindlII. Wild-type DNA digested with endo EcoRI served as a mobility marker for form III DNA (slot E). Following electrophoresis, DNAs were detected by staining with ethidium bromide. The positions of forms I, II, and III and the HindIII 56\% and HindIII 44\% fragments are indicated on the sides. (b) Electrophoresis of $\left[{ }^{32} \mathrm{P}\right] \mathrm{DN} \Lambda \mathrm{s}$ from selected HindIIIresistant, twice plaque-purified stocks. Phenol-extracted Hirt supernatants were prepared from infections of 5 $\mathrm{cm}$ dishes of WME cells (25). DNAs were digested with endo EcoRI (slots marked (a)), or with endo HindIII (slots marked (b)), or with endo EcoRI and endo HindIII (slots marked (c)). After electruphoresis, the gel was dried and autoradiographed.

Many of the stocks of viruses in group II generated form I DNAs that were not equal in size and which could be easily distinguished by electrophoresis through agarose gels. In almost every instance, a DNA without one HindIII site was accompanied by a DNA having an alteration at the other HindIII site. The DNAs could usually be identified by their susceptibility to endo EcoRI or endo BamHI (Table 1). For example, the smaller of two DNAs produced by stock 2-6-1 contained an EcoRI site but had lost the BamHI site; the larger of the two DNAs lacked the EcoRI site but had retained the BamHI site.

Several of the DNAs that were separable by agarose gel electrophoresis have been examined in some detail with endonucleases HpaII and HhaI. In each case, they were found to contain substantial deletions surrounding each of the HindIII sites (28). It is likely that many, if not all, of the mutants in group II contain such deletions and require complementation by co-infecting viruses for growth.

Analysis of the biological properties of 
TARIE 1

Properties of SElected MUTANTS"

\begin{tabular}{|c|c|c|c|c|c|c|c|c|}
\hline \multirow[t]{3}{*}{ Virus stock ${ }^{b}$} & \multicolumn{5}{|c|}{ DNA structure } & \multirow{4}{*}{$\frac{\mathrm{PFU}}{32^{\circ} / 37^{\circ}}$} & \multirow{4}{*}{$\begin{array}{c}\text { DNA } \\
\text { synthe- } \\
\text { sis } 39^{\circ} / \\
32^{\circ k^{\prime}}\end{array}$} & \multirow[t]{3}{*}{ Other $^{h}$} \\
\hline & \multirow[t]{2}{*}{$\mathrm{Size}^{c}$} & \multirow[t]{2}{*}{ Type ${ }^{d}$} & \multicolumn{3}{|c|}{ Fndonuclease sites } & & & \\
\hline & & & EcoRI & HindIII & BamHI & & & \\
\hline \multicolumn{7}{|l|}{ (I) } & & \\
\hline 1-4-1 & 100 & $\mathrm{~S}$ & 1 & 1 & 1 & 2.6 & $=$ & \\
\hline $1-5-1$ & 100 & $\mathrm{~S}$ & 1 & 1 & 1 & 1.7 & $=$ & \\
\hline $1-8-1$ & 100 & $S$ & 1 & 1 & 1 & 2.8 & $=$ & \\
\hline $1-10-1$ & 100 & $\mathrm{~S}$ & 1 & 1 & 1 & 1.2 & $=$ & Small plaque \\
\hline $1-12-1$ & 100 & $\mathrm{~S}$ & 1 & 1 & 1 & 0.4 & $=$ & \\
\hline $1-13-1$ & 100 & $S$ & 1 & 1 & 1 & - & $=$ & \\
\hline $11-14-1$ & 100 & $\mathrm{~S}$ & 1 & 1 & 1 & 2.0 & $=$ & \\
\hline${ }_{\text {(II) }}^{1-2}$ & 100 & $\mathrm{~S}$ & 1 & 1 & - & 4.3 & $=$ & \\
\hline $1-14-1$ & 93 & TEU & 1,0 & 1,1 & 1,0 & 13.7 & $\ll$ & $\begin{array}{l}\text { Multiple-hit kinetics; } \\
\text { small plaque }\end{array}$ \\
\hline $2-23-3$ & 91 & TEU & 1,1 & 1,1 & - & 2.1 & - & \\
\hline $2-12$ & 87 & TEE & $\mathrm{I}, 1$ & 1,1 & 1,0 & - & - & \\
\hline $11-32-1$ & 80 & TEU & 1,0 & 1,1 & 1,0 & 2.0 & $\ll$ & $\begin{array}{l}\text { Multiple-hit kinetics; } \\
\text { small plaque }\end{array}$ \\
\hline $11-33-4$ & 86 & TEU & 1,1 & 1,1 & - & 1.0 & - & Small plaque \\
\hline $1-1-1$ & 85,90 & TUU & - & - & - & 3.4 & - & $\begin{array}{l}\text { Multiple-hit kinetics; } \\
\text { small plaque }\end{array}$ \\
\hline $2-3-1$ & 80,87 & TUE & -0 & 1,1 & $1, \mathbf{I}$ & 3.0 & $\ll$ & \\
\hline $2-6-1$ & $83.5,87.5$ & TUO & 1,0 & 0,1 & 0,1 & - & $\ll$ & \\
\hline $2-15-1$ & $87.5,98$ & TUE & 0,1 & 1,1 &,-- & 1.6 & - & \\
\hline $11-1$ & $77,83.5$ & TUU & 1,0 & 1,1 & 1,1 & - & - & \\
\hline $11-18-3$ & $77,84.5$ & TUU & -- & -- & -- & - & - & Small plaque \\
\hline $11-19-1$ & $73,81.5$ & TUE & 1,0 & 0,0 & $-\cdots$ & 2.2 & - & Small plaque \\
\hline $11-26-1$ & $77.5,78.5$ & TUE & 1,0 & 1,1 & - & - & $\ll$ & \\
\hline $11-31$ & 75,81 & TUE & 1,0 & 0,1 & $-\cdots$ & - & - & \\
\hline $11-35-1$ & $\underline{90,93}$ & TUU & 0,1 & 1,1 & - & 1.5 & - & Small plaque \\
\hline $21-22-1$ & 78,86 & TUE & 1,0 & 1,1 & -- & $>2100$ & $=$ & Thermolabile virion \\
\hline
\end{tabular}

${ }^{2}$ Properties of selected mutants. Viruses lacking HindIII sites are divided into two groups based upon whether they produced single (I) or several (II) species of DNA upon infection of mouse cells.

${ }^{b}$ Virus stocks prefixed by 1 or 11 originated from the endonuclease Hindll digestion of one DNA preparation, and virus stocks prefixed by 2 or 21 originated from the HindIII digestion of a second, independent DNA preparation.

Size expressed as an approximate percentage of wild-type length was determined by examining the mobility of form I viral DNA in 1\% agarose or of linear viral DNA produced by cleavage with a single-site endonuclease (such as EcoRI, BamHI). In group II, the underlined number indicates the predominant species.

${ }^{d} \mathrm{~S}$, single species observed; TEE, two species of equal size and equal quantity; TEU, two species of equal size and unequal quantity; TUE, two species of unequal size and equal quantity; TUU, two species of unequal size and unequal quantity; TUO, two species of unequal size with relative amount of two species ambiguous.

${ }^{\circ}$ Presence or absence of endonuclease sites determined by examining products of digestion of form I DNA after electrophoresis through $1 \%$ agarose. Viruses in group II produce two DNA species; susceptibility of each species is indicated ( 0 , no sites; --, not determined or inconclusive). With TEU mutants, the predominant species is listed first. With TUE or TUU mutants, the smaller species is listed first.

${ }^{f} \mathrm{PFU}$ at $32^{\circ}$ relative to $37^{\circ}$ determined by titering viruses at the two temperatures on monolayers of WME cells. $32^{\circ}$ assays were stained after 21 days; $37^{\circ}$ assays were stained after 12 days.

$g$ Viral DN $\Lambda$ synthesis at 39 and $32^{\circ}$ was examined by measuring the incorporation of ${ }^{32} \mathrm{P}_{\mathrm{i}}$ into viral DN $\Lambda$ in infected WME cells as described in the text. (= indicates equal amounts of incorporation at $39^{\circ}$ and at $32^{\circ}$, or more incorporation at $39^{\circ}$; « indicates very much less incorporation at $39^{\circ}$ than at $32^{\circ}$; and - indicates not done or inclusive).

${ }^{h}$ Effect of dilution upon plaque formation was measured with all the viruses. Those exhibiting "multiple-hit kinetics" produced $10^{-2}-10^{-3}$ fewer plaques upon a $10^{-1}$ dilution. Small plaque morphology was scored visually. Virion thermolability was measured by incubating selected virus stocks at $62.5^{\circ}$ and assaying remaining infectivity at $37^{\circ}$ on WME cells. 
many of the mutants in both groups remains to be performed. Most of the mutants of group I are not noticeably thermosensitive in plaque formation or DNA synthesis (Table 1). Since they are derived from the same preparation of virus, they may be separate isolates of the same mutant. One member of group I (1-10-1), however, does have an altered phenotype. It produces small plaques at both 32 and $37^{\circ}$, and the yield of virus in a single-step growth experiment is significantly lower than that of wild type virus (Fig. 3). If the mutation at HindIII site 1 is the cause of its impaired viability, it is likely that defective early protein(s) are coded by this mutant.

Many of the stocks of mutants in group II were plaque-assayed at 32 and $37^{\circ}$ to determine if their infectivity was thermosensitive. Of those examined, only two showed a significant inhibition of plaqueforming ability at $37^{\circ}$ relative to $32^{\circ}$ (Table 1). One of those produces virions that are thermolabile. After heating at $62.5^{\circ}$ for 8 min, when wild-type polyoma infectivity is reduced 100 -fold, the infectivity of mutant stock 21-22-1 was reduced $10^{3}$ - to $10^{4}$-fold.

Several of the mutant stocks in group II produced plaques at both temperatures which were significantly smaller than those of wild-type virus (Table 1). This may be due to their requirement for co-infection of cells. The titers of several of these viruses deviated extremely from a linear function of dilution as expected for viruses which require co-infection by helpers.

The ability of many of the viruses in both groups to synthesize viral DNA at 32 and $39^{\circ}$ was qualitatively examined by separating the DNAs by agarose gel electrophoresis, and measuring the incorporation of ${ }^{32} \mathrm{P}_{\mathrm{i}}$ into form I DNA at both temperatures. Several of the mutants in group II did not synthesize form I DNA as well at $39^{\circ}$ as at $32^{\circ}$ (Table 1) indicating thermolability of early gene products.

In summary, our preliminary characterization of these mutants suggests that several, if not many of them, will be useful isolates with which to probe functions of the polyoma genome. The mutants in group I may express altered early functions. Further analysis will be required to define the effects of the mutation(s) at the HindIII

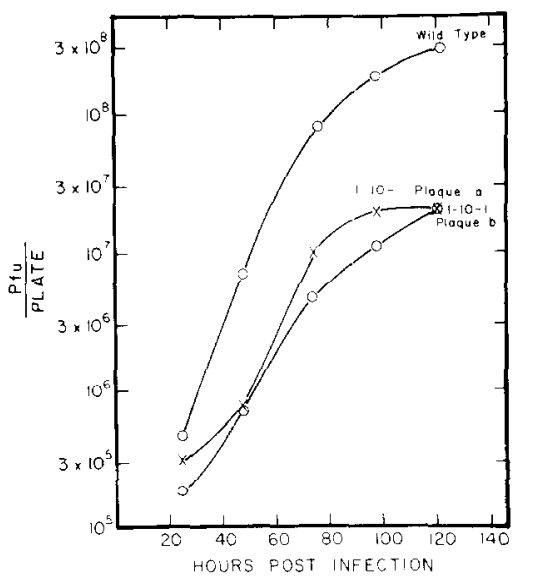

FIG. 3. One-step growth curve of polyoma viruses. WME cells infected with approximately $1 \mathrm{PFU} /$ cell at $33^{\circ}$ were washed with $\mathrm{PBS}$ and incubated at $33^{\circ}$ in medium containing $5 \%$ horse serum. At the indicated times, single plates were harvested by scraping the cells into the medium. The contents of each plate was frozen and thawed three times then titered at $33^{\circ}$ on WME cells. Two separate single-plaque isolates of mutant 1-10-1 were analyzed.

site 1 upon the phenotypes of these viruses. In addition, most of these viruses are capable of proceeding through a normal lytic infection and may, therefore, be more useful as cloning vehicles than wild-type polyoma DNA. (Deletion of HindIII site 1 makes it easier to introduce fragments of DNA in the late region.)

Mutants in group II appear to require complementation for growth. They are altered in the early region or the late region and should prove to be useful in the analysis of polyoma gene functions. However, they are difficult to grow in large amounts and the individual species of the pairs of mutants must be separated before the extents and effects of the alterations can be defined.

\section{ACKNOWLEDGMENTS}

We thank Jane Bancuk and Geoffrey LePlatte for assistance. This study was supported by United States Public Health Service Grant CA13978 from the National Cancer Institute. D.M.A. was supported by Grant GM00187, M.M.B. by Grant GM07315, and W.R.F by an American Cancer Society Faculty Research Award.

\section{REFERENCES}

1. Eckhart, W., Annu. Rev. Genet. 301-317, 1974. 2. Shenk, T. E., Rhodes, C., Rigby, P. W. J., and Berg, P., Cold Spring Harbor Symp. Quant. 
Biol. 39, 61-67, 1974.

3. Gibson, W., Hunter, T., Cogen, B., and EckHART, W., Virology 80, 21-41, 1977.

4. Brockman, W. W., and Nathans, D., Proc. Nat. Acad. Sci. USA 71, 942-946, 1974.

5. LaI, C.-J., and Nathans, D., J. Mol. Biol. 89, 179-193, 1974.

6. Mertz, J. E., Carbon, J., Herzberg, M., Davis, R. W., and BerG, P., Cold Spring Harbor Symp. Quant. Biol. 39, 69-84, 1974.

7. Carbon, J., Shenk, T. E., and Berg, P., Proc. Nat. Acad. Sci. USA 72, 1392-1396, 1975.

8. Carbon, J., Shenk, T. E., and Berg, P., J. Mol. Biol. 98, 1-15, 1975.

9. LAI, C.-J., and Nathans, D., Virology 75, 335-345, 1976.

10. Scott, W. A., Brockman, W. W., and Nathans, D., Virology 75, 319-334, 1976.

11. Rundell, K., Collins, J. K., Tegtmeyer, P., Ozer, H. L., LaI, C.-J., and Nathans, D., J. Virol. 21, 636-646, 1977.

12. Shenk, T., Cell 13, 791-798, 1978.

13. Cole, C. N., Landers, T., Goff, S. P., ManteuilBrutlag, S., and Berg, P., J. Virol. 24, 277-294, 1977.

14. Folk, W. R., and Fished, B. R., Virology 64, 447-453, 1975.
15. Folk, W. R., and WANG, H. E., Virology 61, 140-155, 1974.

16. Griffin, B. E., Fried, M., and Cowie, A., Proc. Nat. Acad. Sci. USA 71, 2077-2081, 1974.

17. Grifrin, B. E., and Fried, M., Nature 256, $175-179,1975$.

18. Kamen, R., and Shure, H., Cell 7, 361-371, 1976.

19. Smith, A. E., Kamen, R., Mangel, W. F., Shure, H., and Wheeler, T., Cell 9, 481-487, 1976.

20. Old, R., Murray, K., and Roizes, G., J. Mol. Biol. 92, 331-339, 1975.

21. Folk, W. R., Fishel, B. R., and Anderson, D. M., Virology 64, 277-280, 1975.

22. Wu, R., JAY, E., and Roychoudhury, R., In "Methods in Cancer Research" (H. Busch, ed.), Vol. 12, pp. 128-160. Academic Press, New York, 1976.

23. Warden, D., and Thorne, H. V., J. Gen. Virol. 3, 371-377, 1968.

24. FolK, W. R., J. Virol. 11, 424-431, 1973.

25. Anderson, D. M., and Folk, W. R., J. Virol. 22, 826-829, 1977.

26. Summers, J., J. Virol. 15, 945-953, 1975.

27. Griffin, B. E., J. Mol. Biol. 117, 447-471, 1977.

28. Anderson, D. M., Ph.D. thesis, The University of Michigan, 1976. 